\title{
Evaluation of Usage of Drugs in Pregnancy at Private Hospitals
}

\author{
Shivani Patel, Karishma Patel, Hely Patel, Utkarsh Gajjar, Shrikalp Deshpande, Akash Mathuria*
}

Department of Pharmacology and Pharmacy Practice, K. B. Institute of Pharmaceutical Education and Research, Gandhinagar, Gujarat, INDIA.

\begin{abstract}
Background: Pregnancy represents a special physiological state during which the use of the drug is inevitable due to the risk of teratogenicity with drugs. The evaluation of prescribing drugs in pregnancy is required due to a lack of knowledge about the harmful effects of these drugs in pregnant women and fetuses. Aim: To evaluate prescribing pattern of drugs and the FDA drug risk category in pregnant women at private hospitals. Materials and Methods: The observational prospective and multicenter study were conducted in 386 pregnant women for 6 months. Each prescription was analyzed for demographic variables, medical illness, antimicrobials, risk categories of drugs prescribed, dosage forms, and WHO prescribing indicators. Results: A total of 2507 drugs were reported in the 637 prescriptions of 386 patients. A large proportion of women had anemia during pregnancy $(42.9 \%)$. Majority of prescriptions prescribed oral dosage forms of drugs $(81.53 \%)$ and injections $(15.59 \%)$. The majority of drugs used in this study were from Category A which included anti-anemic, thyroid therapy drugs, vitamins, and minerals, followed by category $C$ which included calcium supplements, muscle relaxants, and antihypertensive medications. No drugs were prescribed from category X. Conclusion: Iron, Calcium, and Folic acid along with Vitamins and Minerals were the most frequently prescribed drugs. In general, the drug use pattern is rational with few exceptions. The majority of drugs were used from category A followed by Category C. Drugs prescribed by their Brand name were higher than prescribed by their Generic name.
\end{abstract}

Key words: Pregnancy, WHO prescribing indicators, FDA Drug Risk Categories, Antihypertensive medication in pregnancy, Vitamins and Minerals.

\section{INTRODUCTION}

Pregnancy defines a specific physiological state in which the usage of the drug is a major concern due to the possibility of teratogenicity with drugs. In the recent past, most studies have reported an increase in drug use during pregnancy. These unique changes are a challenge to physicians managing states during pregnancy in the selection of medication to treat the patient. Quality information about the safety and efficacy of medication used during pregnancy is lacking for the majority of the prescription drugs available in the market. ${ }^{1-2}$
Medicine is a chemical substance used in the prevention, cure, and treatment of the disease. ${ }^{3}$ Every drug has its pharmacological actions. The pharmacokinetics of certain drugs is altered by the specific physiological change that occurred during pregnancy in the women. ${ }^{4}$ Safety profile of drug used in pregnancy is not directly established in human pregnancy. This is because clinical trial studies of drugs exclude the special population like geriatrics, pediatrics, and pregnant women due to ethical and legal reasons. ${ }^{5}$ Therefore, there is a lack of knowledge and information about the harmful effects of these drugs in pregnant women and fetuses. ${ }^{6}$
DOI: 10.5530/ijopp.14.4.53

Address for

correspondence:

Dr. Akash Mathuria,

Department of Pharmacology and Pharmacy Practice,

K. B. Institute of Pharmaceutical Education and Research, A Constituent College of Kadi Sarva Vishwavidyalaya, Gandhinagar-382024, Gujarat, INDIA.

Phone no: +919157670228 Email id: akashmathuria@ gmail.com

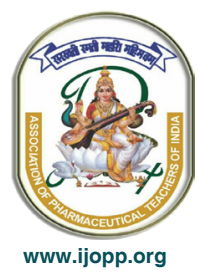


Medication use during pregnancy cannot be avoided since some pregnant women may have chronic pathological conditions like hypertension, diabetes mellitus, thyroid disorders, urinary tract infection, asthma, anemia, allergic reactions, gastrointestinal irritations, hepatitis, jaundice, STDs, and respiratory tract diseases which require treatment. ${ }^{7}$ It is a challenge for the physician to balance the risks and benefits of drug therapy during pregnancy. The usage of drugs during pregnancy is not just limited to the well-being of maternal health but also important for fetal development as well. ${ }^{7}$

The thalidomide tragedy occurred in the 1960s, which is the main reason behind the malformed limbs of thousands of babies during that time. ${ }^{4}$ So, it is important to consider several factors before prescribing a drug in pregnant women, like 1) Dose and frequency of administration of drug, 2) Time of exposure of drug in body, 3) Antimicrobials prescriptions and 4) Teratogenic effect of the prescribing drug. ${ }^{8}$ Prescription pattern monitoring studies (PPMS) is a tool for determining the pattern of prescribing, dispensing, and administering of the medications. The main objective of this study is to encourage the rational use of medications (RUM). These studies also guide and support physicians, pharmacists, and the community for the appropriate usage of drugs.

Prescribing medications during pregnancy is the main concern because of the teratogenic effects of those medications. Study of prescribing pattern of the drug in pregnancy includes age, type of pregnancy like singleton and multiple, number of pregnancies, number of gravida and parity, abortion, trimester, risk category, concomitant condition. The regulation of prescription drugs in pregnancy is done by US FDA and WHO. The US FDA has regulating drug labeling, the use of medications in pregnancy, requiring proper demonstrations of the safety and efficacy of any drug before it comes to the market. ${ }^{9}$ In the year 1979, the US FDA defines drug risk categories based on the possibility of a medication to cause birth deformities if used during pregnancy. These categories were established by assessing the risk-to-benefit ratio and well-controlled studies. ${ }^{4}$

Evaluation of drugs used in pregnancy is very essential because the use and availability of medications are changing time by time. Changing maternal characteristics play an important role in the prescription of a drug during pregnancy. ${ }^{5}$ The main goal of this study is to define how commonly medicines are used during the gestation period based on US FDA risk category, describe the prescribing indicator, which is most often used medicines in $1^{\text {st }}, 2^{\text {nd }}$, and $3^{\text {rd }}$ trimester, and to check the prescribing pattern of drugs used during pregnancy. The study might help to improve rational drug prescribing in the prenatal period.

\section{MATERIALS AND METHODS}

\section{Type of Study Design}

Observational, prospective and multicenter study.

\section{Study Site/Location}

No. of sites: 4

1. Gayatri Hospital, Gandhinagar

Contact Person: Dr. Ratnesh Patel

Site Address: 653/1, G Rd, Sector 6-b, Gandhinagar.

2. Geeta Maternity Home, Gandhinagar

Contact Person: Dr. Bhavik Modi

Site Address: Plot No 951/1, Sector 7-C, Gandhinagar.

3. Subham Maternity Hospital, Gandhinagar

Contact Person: Dr. Nisha Goswami

Site Address: Sector 8, Gandhinagar

4. Ukti Maternity Hospital, Gandhinagar

Contact Person: Dr. Chirag Joshi

Site Address: 735/3, Sec 22, Gandhinagar.

\section{Sample Size}

Convenient sample size that matches the eligibility criteria (inclusion and exclusion criteria) throughout data collection period.

\section{Study Duration}

06 months of study out of which 04 months were for data collection and 02 months for data analysis and project write-up.

\section{Designing of Study Related Documents}

Predesigned study materials approved from institutional ethics committee were used for data collection and analysis. It includes:

\section{Data Collection Form}

Following information and variables are included in data collection form. This will be used to collect data from patient file.

A. General information: it includes study site, patient ID no, date. 
B. Patient demographic data: age, weight, height, BMI, marital status, residential address, education level and employment.

C. Pregnancy status: it includes number of pregnancy, weeks of pregnancy, pre-term, gestation age (in trimester), GPAL, types of pregnancy-singleton/multiples.

D. Social and medical History or any other significant detail.

E. Medication history: it includes name of drug, dose, route of administration, frequency, class, indication.

F. Laboratory data: it includes abnormal test, reference range, initial, follow-up 1 and 2.

G. Concomitant condition (if any).

H. Current medication chart: it includes name of drug (generic/brand name), formulation, dose, and route of administration, frequency, start and stop date, WHO pregnancy risk category, comment (if any).

2. Patient Information Sheet- English And Guajarati Language

The patient information sheet in English and vernacular language (Gujarati) had been provided to the patient before enrolling them to study which explains them in brief about type of the study, purpose of the study, confidentiality and study procedure.

\section{Informed Consent Form-English And Gujarati} Language

Before enrolling the patient in the study, an informed consent form was signed by patient to take all the study population as a proof of their voluntary participation.

\section{Eligibility Criteria for the Study}

\section{Inclusion Criteria}

$>$ Pregnant patient comprising of child bearing age. (18 to 45 years)

$>$ Patients who were willing to participate in study.

\section{Exclusion Criteria}

Lactating women

\section{Study Approvals}

Prior to the study, it was necessary to take the approval/ permission from the ethics committee of KBIPER, KSV
University to conduct the following study in 4 private hospitals of Gandhinagar.

\section{Data Collection}

The data was collected during an individual interview of pregnant women who were on drugs and came to visit the physician. The patients were informed about the study-type, risk, benefits, etc., and an informed consent form was signed by a patient or patient's representative.

A data collection form was filled by investigators which comprise of patient's demographic details, medical and social history, medication chart (frequently used class of drugs with its formulation, antibiotics, and generic/ brand medications), and concomitant conditions during pregnancy and check whether prescribed according to US FDA risk category.

\section{Data Evaluation}

The data was assessed and evaluated to obtain following set of criteria.

\section{WHO prescribing Indicators}

Average number of medicines per prescription.

Percentage of generic medications prescribed.

Percentage of an antibiotic prescribed.

Percentage of drugs prescribed from WHO pregnancy drug risk category.

\section{Category wise description}

Category A: Adequate and well-controlled studies in pregnant women have failed to demonstrate a risk to the fetus in the first trimester of pregnancy (and there is no evidence of risk in later trimesters).

> Category B: Animal reproduction studies have failed to demonstrate a risk to the fetus and there are no adequate and well-controlled studies in pregnant women.

Category C: Animal reproduction studies have shown an adverse effect on the fetus and there are no adequate and well-controlled studies in humans, but potential benefits may warrant use of the drug in pregnant women despite potential risks.

Category D: There is a positive evidence of human fetal risk based on adverse reaction data from 
investigational or marketing experience or studies in humans, but potential benefits may warrant the use of a drug in pregnant women despite potential risks.

Category X: Studies in animals and humans have demonstrated fetal abnormalities and/or there is positive evidence of human fetal risk based on adverse reaction data from investigational or marketing experience and the risks involved in use of the drug in pregnant women clearly outweigh potential benefits.

III. Drug use according to Formulation Prescribed

$>$ Oral formulation: The dosage form designed to be taken through mouth.

Parenteral preparations: They are sterile preparations containing one or more active ingredients intended for administration by injection, infusion or implantation into the body. They can be given by various routes like intravenous, intramuscular, subcutaneous etc.

$>$ Other than oral and parenteral preparations.

\section{Statistical Analysis}

Statistical analysis was carried out by using MS Office Excel 2013 (v15.0). Descriptive analysis was represented in mean with standard deviation, frequency and percentage.

\section{RESULTS}

Table 1 shows the age of patients ranging from 19-39 years. The maximum number of study population belonged to age group 23-27 (44.11\%) and the minimum number of study population belonged to age group $38-42(0.94 \%)$. out of 637 prescriptions, $44.42 \%$ of the study population were graduates and $15.85 \%$ of the study population were post-graduate and only $2.35 \%$ of patients were illiterate. 15 pregnant women had a history of smoking. the Maximum number of prescriptions belonged to $3^{\text {rd }}$ trimester. More than half pregnant women were primigravida (55.42\%). This table shows that $86.50 \%$ of prescriptions had no previous history of abortion or miscarriage. $99.37 \%$ study population had a singleton pregnancy. From 637 prescriptions $2.98 \%$ of study population were at risk to have Down syndrome to the baby and premature delivery.
Table 1: Socio-Demographic and Pregnancy Related Details of Study Population ( $N=637$ ).

Frequency(n) Percentage (\%)

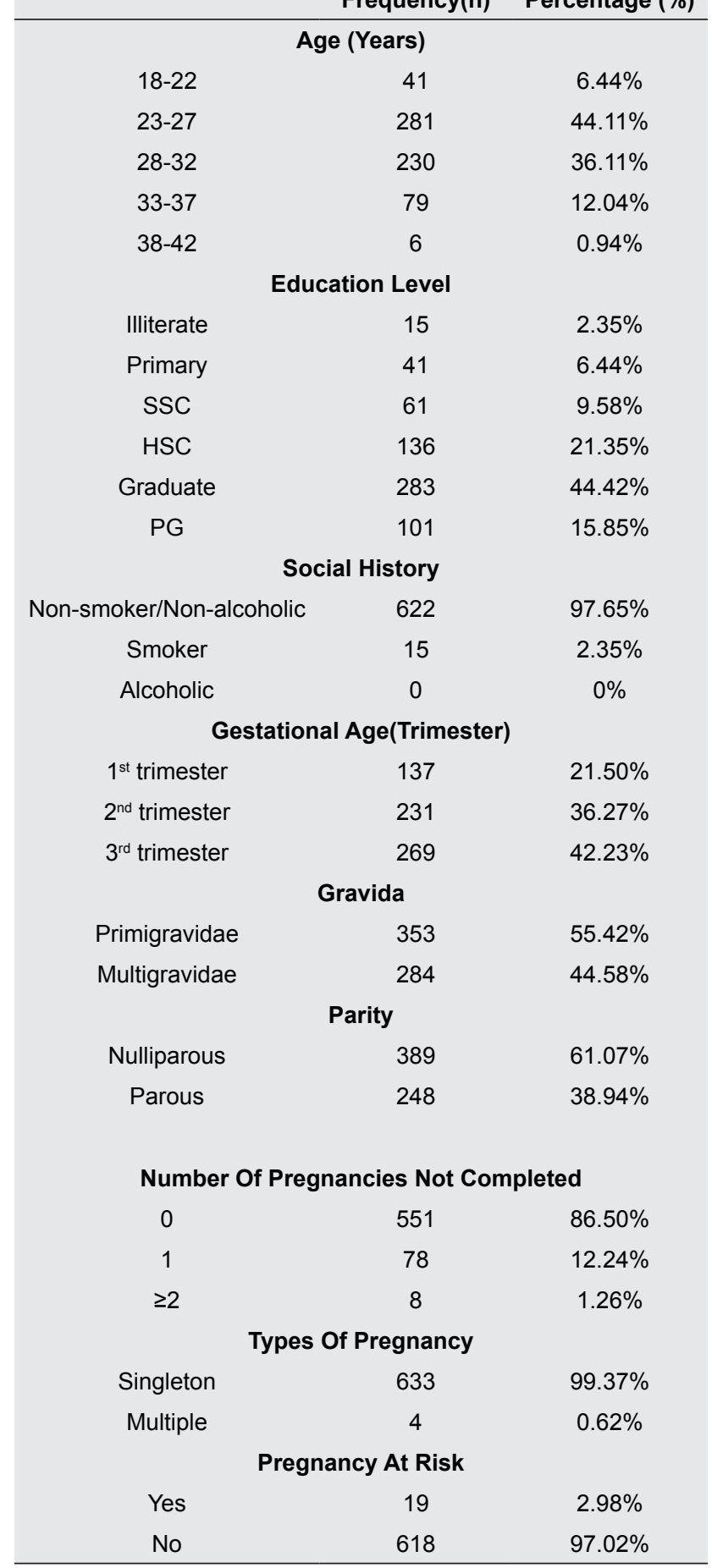

Table 2 shows the medical illness present in pregnant women at before and during pregnancy. It indicates that the number of diseases increased during pregnancy. Before the pregnancy, the number of diseases was less than during pregnancy. The data of anemia before the pregnancy was not available but a majority of women were anemic during pregnancy. Other diseases includehypertension, diabetes, UTI, thyroid disorders, etc. 
Figure 1 shows that total of 2507 drugs were prescribed by the physician in 637 prescriptions. Amongst them, multivitamins/minerals were prescribed throughout the trimesters. In the $1^{\text {st }}$ trimester 75\% anti-emetic, $54.70 \%$

Table 2: Study of Medical IIIness before and During Pregnancy in the study population ( $\mathrm{N}=637$ ).

\begin{tabular}{cccc}
$\begin{array}{c}\text { Sr. } \\
\text { no. }\end{array}$ & Disease & $\begin{array}{c}\text { Before } \\
\text { pregnancy }\end{array}$ & $\begin{array}{c}\text { During } \\
\text { pregnancy }\end{array}$ \\
\hline 1 & Anemia & unknown & 270 \\
2 & Hypertension & 8 & 17 \\
4 & Hypothyroidism & 8 & 17 \\
6 & UTI & 6 & 12 \\
3 & Hyperthyroidism & 2 & 10 \\
5 & Diabetes & 0 & 2 \\
\hline
\end{tabular}

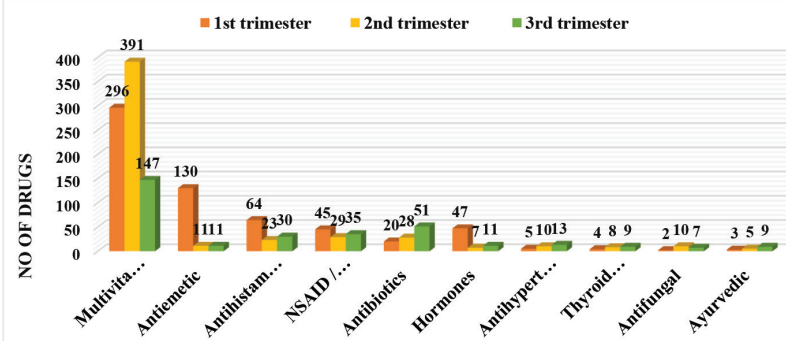

Figure 1: Drug Distribution in Study Population Based On Therapeutic Class $(\mathrm{N}=1461)$. anti-histamines /PPIs and 41.28\% NASIDs/analgesic usage were reported in these pregnant women. In the $2^{\text {nd }}$ trimester and $3^{\text {rd }}$ trimester $46.88 \%$ multivitamins and $28.28 \%$ antibiotics were used. Hormonal (progesterone and estrogen) supplements were maximum used in the $1^{\text {st }}$ trimester. Other drugs like antihypertensive and thyroid hormones were maximum used in $3^{\text {rd }}$ trimester. Out of 2507 drugs, only 17 Ayurvedic supplements were administered by the study population.

Table 3 shows out of 1993 drugs iron, calcium, folic acid, and vitamin $B_{12}$ were throughout used in all the trimesters in the study population. Tetanus toxoid was only used in the $2^{\text {nd }}$ trimester. Amongst all the trimesters Doxylamine and pyridoxine $(90.38 \%)$, Pantoprazole (50.65\%), Azithromycin (33.33\%), Progesterone (90\%), Paracetamol (81.82\%), Levocetirizine (51.56\%), and Ondansetron $(78.05 \%)$ were used more in $1^{\text {st }}$ trimester. Levothyroxine (41.17\%), Itraconazole (83.33\%), and Dicyclomine $(66.66 \%)$ were used more in $2^{\text {nd }}$ trimester. Cefixime (75\%), labetalol (50\%), and Propylthiouracil $(75 \%)$ were used more in $3^{\text {rd }}$ trimester. Isoxsuprine was only used in $3^{\text {rd }}$ trimester in the study population.

Figure 2 shows the proportion of drugs based on the FDA drug risk category. We used Micromedex 2.0 for searching the drug risk category. Category $A$ and category

\begin{tabular}{|c|c|c|c|c|c|}
\hline Sr. No. & Drug name & Total & $1^{\text {st }}$ trimester No (\%) & $2^{\text {nd }}$ trimester No (\%) & $3^{\text {rd }}$ trimester No $(\%)$ \\
\hline 1 & Tetanus toxoid & 360 & 0 & $360(100 \%)$ & 0 \\
\hline 2 & Calcium & 354 & $104(29.37 \%)$ & $222(62.71 \%)$ & $27(7.63 \%)$ \\
\hline 3 & Iron & 285 & $79(27.72 \%)$ & 117 (41.05\%) & $89(31.23 \%)$ \\
\hline 4 & Folic acid & 246 & $122(49.59 \%)$ & $94(38.21 \%)$ & $30(12.19 \%)$ \\
\hline 5 & Vitamin B12 & 162 & $57(35.19 \%)$ & $47(29.01 \%)$ & $58(35.80 \%)$ \\
\hline 6 & Doxylamine & 104 & $94(90.38 \%)$ & $6(5.76 \%)$ & $4(3.85 \%)$ \\
\hline 7 & Pantoprazole & 77 & $39(50.65 \%)$ & $17(22.08 \%)$ & $21(27.28 \%)$ \\
\hline 8 & Azithromycin & 54 & $18(33.33 \%)$ & 17 (31.48\%) & $19(35.18 \%)$ \\
\hline 9 & Progesterone & 50 & $45(90 \%)$ & $5(10 \%)$ & 0 \\
\hline 10 & Levocetirizine & 48 & $33(51.56 \%)$ & $13(20.31 \%)$ & $18(28.12 \%)$ \\
\hline 11 & Paracetamol & 44 & $36(81.82 \%)$ & $5(11.37 \%)$ & $3(6.82 \%)$ \\
\hline 12 & Ondansetron & 41 & $32(78.05 \%)$ & $4(9.76 \%)$ & $5(12.19 \%)$ \\
\hline 13 & Aspirin & 33 & $13(39.39 \%)$ & $12(36.36 \%)$ & $8(24.24 \%)$ \\
\hline 14 & Isoxsuprine & 31 & 0 & 0 & $31(100 \%)$ \\
\hline 15 & Ranitidine & 28 & $20(71.42 \%)$ & $4(14.28 \%)$ & $4(14.28 \%)$ \\
\hline 16 & Cefixime & 24 & 0 & $6(25 \%)$ & $18(75 \%)$ \\
\hline 17 & Labetalol & 18 & $3(16.66 \%)$ & $6(33.33 \%)$ & $9(50 \%)$ \\
\hline 18 & Levothyroxine & 17 & $4(23.53 \%)$ & $7(41.17 \%)$ & $6(35.29 \%)$ \\
\hline 19 & Nifedipine & 10 & $2(20 \%)$ & $4(80 \%)$ & $4(80 \%)$ \\
\hline 20 & Itraconazole & 6 & 0 & $5(83.33 \%)$ & $1(16.66 \%)$ \\
\hline 21 & Propylthiouracil & 4 & 0 & $1(25 \%)$ & $3(75 \%)$ \\
\hline 22 & Dicyclomine & 3 & 0 & $2(66.66 \%)$ & $1(33.33 \%)$ \\
\hline
\end{tabular}




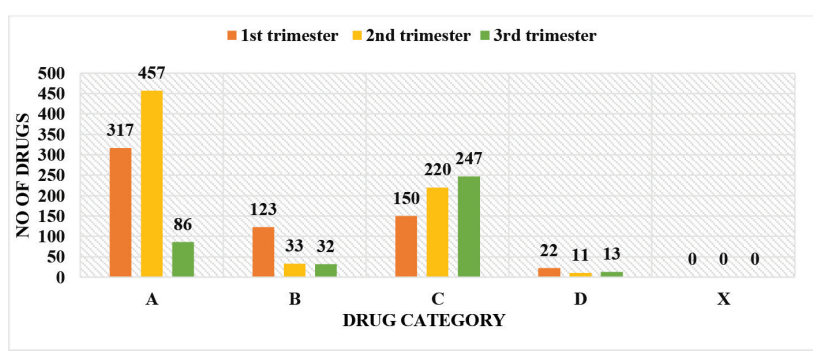

Figure 2: Distribution of drugs according to FDA drug risk category $(n=1711)$.

\begin{tabular}{|c|c|c|}
\hline $\begin{array}{l}\text { Sr. } \\
\text { No. }\end{array}$ & Indicator & Value \\
\hline 1 & Total number of patients analyzed & 386 \\
\hline 2 & Total number of drugs prescribed & 2507 \\
\hline 3 & $\begin{array}{l}\text { Average number of drugs per } \\
\text { prescription }\end{array}$ & 3.32 \\
\hline 4 & $\begin{array}{l}\text { Percentage of drugs prescribed by } \\
\text { generic name }\end{array}$ & $4.06 \%$ \\
\hline 5 & $\begin{array}{l}\text { Percentage of encounters with } \\
\text { antibiotic prescribed }\end{array}$ & $4.68 \%$ \\
\hline 6 & $\begin{array}{l}\text { Percentage of encounters with an } \\
\text { injection prescribed }\end{array}$ & $1.47 \%$ \\
\hline
\end{tabular}

C drugs were prescribed in higher amount. Category a drugs were prescribed more in the $2^{\text {nd }}$ trimester while category $\mathrm{C}$ drugs were prescribed to a greater extent in the $3^{\text {rd }}$ trimester of the study population. Category B drugs were more prescribed in the $1^{\text {st }}$ trimester. Category $\mathrm{D}$ drugs were less prescribed throughout the study. Category X drugs were not prescribed in any trimester throughout the study population. In this study, some drugs were also prescribed for which FDA drug risk category was not ruled out.

Table 4 shows the prescribing indicator values in our study.

\section{DISCUSSION}

Maternal medication use in pregnancy could cause teratogenicity to the fetus, however, it could be dangerous if the recommendation of drug usage is avoided during pregnancy. ${ }^{7}$ Rational use of the drug in pregnancy requires balancing of benefit-to-risk ratio related with the use of drugs. To collect complete information on prescribing patterns of pregnant women, this prospective multicenter study was performed in 4 tertiary health care setups (1. Gayatri Hospital, Gandhinagar, 2. Geeta Maternity Home, Gandhinagar, 3. Subham Maternity Hospital, Gandhinagar, 4. Ukti Maternity Hospital, Gandhinagar). This study helped us to understand the current drug utilization practices in antenatal practice in the tertiary health care setups. Evaluation of drug prescribing indicators and simultaneously the drug risk categorization of prescribed drugs by US-FDA is done by us. In our study, 637 prescriptions of 386 patients were evaluated for 6 months. Total 2507 drugs were reported in the 637 prescriptions. The mean age of the patient was $28 \pm 1.41$ years, and commonest age group was between 28 to 32 years which was comparatively similar with the other prospective studies. ${ }^{10-11}$ [Table 1] Greater than half of study population was primigravida $(55.42 \%)$ in this present study which is nearly similar to other study performed in South India. ${ }^{12}$ [Table 1] Total $13.50 \%$ of women had a previous history of abortion or miscarriage. Most of the study population were in the $3^{\text {rd }}$ trimester $(42.23 \%$ ), while $21.50 \%$ were in the $1^{\text {st }}$ trimester and $36.27 \%$ were in the second trimester. The maximum number of the study population has a singleton pregnancy [Table 1] and $2.98 \%$ of study population was at risk of having premature delivery and chances of Down syndrome to the baby were seen as mentioned in Table 1. More than half of pregnant women were came for a routine checkup in OPD, with no complaints. Supplementary drugs which included vitamins, iron, folic acid, calcium, and minerals are essential in preventing malnourishment of fetus and mother. In the present study, higher amount of women had anemia (75\%) during pregnancy. [Table 2 and 3] This was the main reason why iron and supplementary drugs were more prescribed to the patients. In this study, an iron supplements prescribed throughout the pregnancy was 276. [Table 3] Calcium supplements were more prescribed in the 2 nd trimester $(n=222)$ for the fetal bone development. [Table 3] The number of folic acid prescribed was 249 out of which 122 were prescribed in $1^{\text {st }}$ trimester to avoid birth defects of brain (neural tube defects) known as anencephaly that commonly occur in an early stage of pregnancy and cause fetal growth retardation. [Table 3] $400 \mathrm{mcg}$ of folic acid is necessary for fetus brain and spine development. ${ }^{13}$ Vitamin B12 was majorly prescribed in the $1^{\text {st }}$ and $3^{\text {rd }}$ trimesters to prevent vitamin B12 deficiency in women and to prevent Spina bifida and other spinal and nervous system deformities to the fetus. ${ }^{14}$ Detection of anemia and malnourishment at an early stage of pregnancy can avoid the risks associated with morbidity during pregnancy. ${ }^{14}$ The next common categories of drugs were antihistamine and proton pump inhibitors. Levocetirizine $(n=48)$ was prescribed for allergic conditions and Pantoprazole $(n=77)$ was given for gastrointestinal irritations as mentioned in Tables 3 . From the present study, we found that 152 antiemetics were prescribed for the major complaints of nausea and 
vomiting. Doxylamine succinate and pyridoxine were the most prescribed in our study $(n=104)$ followed by Ondansetron ( $n=41)$ followed by Domperidone $(n=7)$ as demonstrated in Table 3. Doxylamine and pyridoxine are the only FDA-approved drug for treatment of nausea and vomiting during pregnancy. ${ }^{15}$ Canadian guidelines also recommended Doxylamine-Pyridoxine as the firstline treatment for pregnancy associated nausea and vomiting. These results varied when compared to other studies. ${ }^{16}$ Urinary tract infections, respiratory tract infections, and fungal infections were reported in study population $4.68 \%$ of antibiotics were prescribed, [Table 4] which were in contrast to two previous studies that reported comparatively more use of antibiotics $17.9 \%$ and $8.10 \%$ in Anantapur (AP, India) and the coastal town of South India in the year of 2017 respectively. ${ }^{12-17}$ Azithromycin $(n=54)$ and Cefixime $(n=24)$ were the most prescribed drugs throughout the study. [Table 3] Both the antimicrobial agents belonged to category $\mathrm{B}$ which indicates safe use in patients. Doxycycline, a Category $\mathrm{D}$ drug that has proven teratogenic risk was prescribed in 3 prescriptions, which should be avoided. Some pregnant women were already on some medications before pregnancy due to their disease conditions. They were continuing those during their gestation or switch to another safe medication. Gestational hypertension was reported in our study population $(n=17)$ for that antihypertensive medications were prescribed. It included labetalol $(n=18)$ and Nifedipine $(n=10)$ which were the drug of choice for hypertension in pregnancy and it belonged to category $\mathrm{C}$ (prescribed by calculating risk-benefit ratio). Thyroid disorders were also reported in our study population $(n=27)$, in which hypothyroidism was very common $(n=17)$. The detail of drugs prescribed for thyroid disorders was shown in Table 3. For gestational diabetes mellitus, the physician preferred tablet metformin. $(n=3)$ [Table 3] Analgesics and NSAIDs like Paracetamol $(n=44)$, Aspirin $(n=33)$, Aceclofenac $(n=9)$, Diclofenac $(n=34)$ were given to treat fever and pain during pregnancy. They were not yet classified by FDA in the drug risk category but exposure to NSAIDs after 30 weeks gestation is responsible for higher risk of premature closure of the fetal ductus arteriosus and dilation of fetal afferent renal arterioles which leads to decrease fetal GFR. ${ }^{18}$ Isoxsuprine was used for management of threatened premature labor in pregnancies of more than 20 weeks gestation. In our study, the Isoxsuprine was prescribed only in $3^{\text {rd }}$ trimester which is safe for pregnant women. $(n=31)$ [Table 3] Tetanus Toxoid intramuscular injections were given to every pregnant woman in $2^{\text {nd }}$ trimester as prophylaxis $(n=360)$.

Indian Journal of Pharmacy Practice, Vol 14, Issue 4, Oct-Dec, 2021
A noticeable fact was that the average number of medicines prescribed per prescription is 3.32. [Table 4] Percentage of drugs prescribed by generic name was only $4.06 \%$ as mentioned in Table 4. This study manifest a higher tendency to prescribe drugs by their brand name rather than by generic name. In this study percentage of antibiotics prescribed was $4.68 \%$, which was lower in comparison with other studies.

Using the US-FDA risk classification, the percentage of women receiving drugs from different classes was documented. The majority of drugs prescribed in this study were from Category A $(n=860)$ which included anti-anaemics, thyroid therapy drugs, vitamins and minerals, followed by category C $(n=617)$ which included calcium supplements, muscle relaxants like Isoxsuprine, antihypertensive medications like Labetalol and Nifedipine. Few prescriptions have Category B $(n=188)$ drugs which showed no risk to the fetus in the animal studies. Category B drugs included Antibiotics such as Penicillins, $3^{\text {rd }}$ generation Cephalosporines, Azithromycin, and antiemetics. The usage of Category D drugs like Doxycycline $(n=4)$, Alprazolam $(n=2)$ were observed in the study population. Though they were not used widely, they should be avoided in pregnancy as more safe drugs were available. No drugs were prescribed from category $\mathrm{X}$ as demonstrated in Figure 2. A similar pattern of category distribution was reported in other studies. Thus, overall it can be said that a drug prescribing pattern during pregnancy was safe in our study population. More such studies should be done to know more about the prescribing pattern and education and awareness regarding the safe use of drugs should be given to the obstetricians. ${ }^{19}$ Adequate knowledge, positive approach, and awareness towards rational drug use are essential for well-being of mother as well as child. It has become important to examine the pattern of drug utilization in pregnancy, to check up to what extent there may be need for improvement in the light of current knowledge. ${ }^{20}$ Even the physician needs to be trained to give rational treatment to pregnant women. This will aid in providing directions to rational drug usage in the community.

\section{CONCLUSION}

In this study, the total number of patients enrolled was 386 with 637 prescriptions. The total number of drugs prescribed in this study population was 2507 . The average number of drugs per encounter was 3.32. The percentage of drugs prescribed by generic name was $4.06 \%$. The percentage of antibiotics prescribed in these patients was $4.68 \%$. The percentage of injections 
prescribed in these patients was $15.59 \%$. A major amount of the drugs were prescribed from FDA Category A, which is the safest category during pregnancy. Drugs of Category $\mathrm{C}$ were prescribed in large numbers assessing the risk-benefit ratio of the fetus. No woman was prescribed Category X drug.

\section{ACKNOWLEDGEMENT}

In the accomplishment of this project successfully, we would sincerely like to thank each and every one who has helped and supported us for the successful completion of our project. We express our sincere thanks to our guide Dr. Shrikalp Despande and co-guide Dr. Akash Mathuria for their support and guidance. Their guidance and their instructions have served as a major contribution towards the completion of the project.

We are grateful to Dr. Ratnesh Patel, Dr. Bhavik Modi, Dr. Nisha Goswami, and Dr. Chirag Joshi Tailor for giving us an opportunity and permitting us to carry out this project at Gayatri Hospital, Geeta Maternity Home, Shubham Hospital, Ukti Maternity Hospital respectively. We also extend our thanks to all staff members for their kind cooperation in the conduct of the study.

We extend our sincere gratitude to Dr. Sandipkumar Bhatt for their valuable guidance and suggestions for our study.

We are immensely grateful to KBIPER who has sponsored our study and supported us a lot throughout the study for its timely completion.

\section{CONFLICT OF INTEREST}

The authors declare no conflict of interests.

\section{ABBREVIATIONS}

PPMS: Prescription pattern monitoring studies; RUM: Rational use of medicines; FDA: Food and drug administration; WHO: World health organization; LMP: Last menstrual period; BMI: Body Mass Index; GPAL: Gravida, Parity, Abortion, Living; KBIPER: K. B. Institute of Pharmaceutical Education and Research; KSV: Kadi Sarv Vidhyalaya; SD: Standard deviation; SSC: Secondary school certificate; HSC: Higher secondary certificate; PG: Post Graduate; UTI: Urinary Tract Infection; PCOD: Polycystic Ovary Disease; PPI: Proton Pump Inhibitor; NSAID: Non-Steroidal Anti-
Inflammatory Drug; OD: Once a day; BD: Twice a day; TID: Thrice a day; SOS: Si Opus Sit (If Needed); MVI: Multi-Vitamin Injection; MDI: Metered Dose Inhaler.

\section{SUMMARY}

The evaluation of usage of drugs in pregnancy is required due to the lack of knowledge about the harmful effects of drugs in pregnant women as well as in fetus. Rational use of the drug in pregnancy requires balancing of benefitto-risk ratio related with the use of drugs. To collect the complete information about prescribing patterns of drugs during pregnancy, this observational, prospective and multicenter study was performed in 4 tertiary health care setups of Gandhinagar, Gujarat. This study helped us to understand the current drug utilization practices in tertiary health care setups. Evaluation of drug prescribing indicators and the US-FDA drug risk categorization of prescribed drugs were done by us. The study was conducted in 386 pregnant women for 6 months. During this period, these prescriptions were analyzed for different parameters like demographic details, medical illness, FDA drug risk categories of prescribed drugs, dosage forms and WHO prescribing indicators. As a result of this study, a total of 2507 drugs were reported in 637 prescriptions of 386 patients. The majority of drugs used from category A, which is the safest category of drugs, followed by category $\mathrm{C}$, which is prescribed by assessing the risk-to-benefit ratio. No drugs were prescribed from category $\mathrm{X}$. The majority of drugs prescribed by their brand name rather than by generic name. Amongst all the dosage forms, oral dosage forms used more in the study population. Thus, overall it can be said that a drug prescribing pattern during pregnancy was safe in our study population. More such studies should be done to know more about the prescribing pattern and the safe use of drugs during pregnancy.

\section{REFERENCES}

1. Joshi H, Patel S, Patel K, Patel V. Drug use pattern during pregnancy: A prospective study at tertiary care teaching hospital. NHL J Med Sci. 2012 Jul;1(1):14-7.

2. Gawde SR, Bhide SS, Patel TC, Chauhan AR, Mayadeo NM, Sawardekar SB. Drug prescription pattern in pregnant women attending antenatal outpatient department of a tertiary care hospital. J Pharm Res Int. 2013:1-2.

3. das S, blessed winston a2, deepasree sukumaran1, aniket kumar3, margaret shanthi $\mathrm{fx} 4$ and jasmin prasad. Drug prescribing pattern in pregnancy in a secondary care hospital in south India: a retrospective study. SAGE. 2016;46(2): 86-90.

4. Das S, Winston AB, Sukumaran D, Kumar A, Fx MS, Prasad J. Drug prescribing pattern in pregnancy in a secondary care hospital in south India: a retrospective study. Trop Doct. 2016 Apr;46(2):86-90. doi: 10.1177/0049475515609841, PMID 26450430.

5. Al-Hamimi JZ, Al Balushi KA. Patterns of prescription drugs use among pregnant women at Sultan Qaboos University Hospital and Sultan Qaboos 
University Hospital family and community medicine clinic, Oman. J Pharm Bioallied Sci. 2016 Oct;8(4):309-13. doi: 10.4103/0975-7406.199347, PMID 28216955.

6. Burkey BW, Holmes AP. Evaluating medication use in pregnancy and lactation: what every pharmacist should know. J Pediatr Pharmacol Ther. 2013 Sep;18(3):247-58. doi: 10.5863/1551-6776-18.3.247, PMID 24052789.

7. Varghese $B M, K V$, Banu R. Assessment of drug usage pattern during pregnancy at a tertiary care teaching Hospital. IJMEDPH. 2016;6(3):130-5. doi: 10.5530/ ijmedph.2016.3.7.

8. Jainaf NRAM, Parimalakrishnan S, Ramakrishna RM. M. Study on drug utilization pattern of antihypertensive medications on out-patients and inpatients in a tertiary care teaching hospital: A cross sectional Study. Afr J Pharm Pharmacol. 2015;9(11):383-96. doi: 10.5897/AJPP2014.4263.

9. Jain S, Upadhyaya P, Goyal J, Kumar A, Jain P, Seth V, Moghe VV. A systematic review of prescription pattern monitoring studies and their effectiveness in promoting rational use of medicines. Perspect Clin Res. 2015;6(2):86-90. doi: 10.4103/2229-3485.154005, PMID 25878953.

10. Yadav S, Evangeline GS. A study on prescribing pattern of drugs in pregnant women attending a teaching hospital. Int J Pharmacol Ther. 2016;6(1):9-26.

11. Lazarus JH. Management of hyperthyroidism in pregnancy. Endocrine. 2014 Mar 1;45(2):190-4. doi: 10.1007/s12020-013-0086-9, PMID 24174179.

12. Sasidharan P, Kolasani BP, Cm D. An observational prospective study on prescribing pattern of drugs among pregnant women admitted in antenatal ward of a tertiary care teaching hospital in coastal town of South India. Natl J Physiol Pharm Pharmacol. 2017;7(1):25. doi: 10.5455/njppp.2016.6.0616412072016.
13. Folic acid- Theresa O Scholl, William G Johnson, folic acid: influence on the outcome of pregnancy. Am J Clin Nutr;71(5, May):1295S-303S.

14. Shojania AM. Folic acid and vitamin B12 deficiency in pregnancy and in the neonatal period. Clin Perinatol. 1984;11(2):433-59. doi: 10.1016/S00955108(18)30928-X, PMID 6378487.

15. Lowes RFDA. Approves Diclegis as first morning sickness drug in 30 years. Medscape Med News. April 9. 2013.

16. Arsenault MY, Lane CA, MacKinnon CJ, Bartellas E, Cargill YM, Klein MC, Martel MJ, Sprague AE, Wilson AK. The management of nausea and vomiting of pregnancy. J Obstet Gynaecol Can. 2002;24(10):817-31; quiz 32-3. PMID 12405123.

17. Sunanda G, Ali Al, Suchitra J, Narayana G, Ramaiah D. Assessment of WHO Core Drug Use Indicators and Drug Utilization pattern in Obstetrics and Gynaecology Department of Secondary Care Referral Hospital. Int J Pharm Pract Drug Res. 2017;7(1):8-13.

18. Antonucci R, Zaffanello M, Puxeddu E, Porcella A, Cuzzolin L, Pilloni MD, Fanos $V$. Use of non-steroidal anti-inflammatory drugs in pregnancy: impact on the fetus and newborn. Curr Drug Metab. 2012 May 1;13(4):474-90. doi: 10.2174/138920012800166607, PMID 22299823.

19. Engeland A, Bjørge T, Klungsøyr K, Hjellvik V, Skurtveit S, Furu K. Trends in prescription drug use during pregnancy and postpartum in Norway, 20052015. Pharmacoepidemiol Drug Saf. 2018 Sep;27(9):995-1004. doi: 10.1002/ pds.4577, PMID 29920833.

20. Kureshee NI, Dhande PP. Awareness of mothers and doctors about drug utilization pattern for illnesses encountered during pregnancy. J Clin Diagn Res. 2013;7(11):2470-4. doi: 10.7860/JCDR/2013/6329.3582, PMID 24392375. 